\title{
The Effect of Using STEAM Approach on Developing Computational Thinking Skills among High School Students in Jordan
}

\author{
https://doi.org/10.3991/ijim.v14i14.14719 \\ Rana Al-Haj Bedar \\ Philadelphia National Schools, Amman, Jordan \\ Muhannad Al-Shboul $(\square)$ \\ The University of Jordan, Amman, Jordan \\ malshboul@ju.edu.jo
}

\begin{abstract}
The growing demand for combining digital technology with learning practices has surpassed the use of technology or learning how to use it into the process of enhancing learners' intellectual levels and scaffolding their understanding by focusing on skills that include thought processes gathered in what is called computational thinking. On the other hand, educational challenges promote the search for new instructional tools and approaches. Consequently, learning shall be extended by superimposing science, technology, engineering, arts, and mathematics (STEAM) approach in the instructional practices. The aim of this paper is to show how STEAM approach can develop the computational thinking among high school learners. The main skills of computational thinking included: algorithmic thinking, abstraction, decomposition, and generalization. The sample of this study involved 32 high school students in a private school in Amman. The experimental group studied geography skills in a STEAM approach that included the use of online resources such as LightBot maze and the Ordnance Survey maps (OS) website. The control group studied the same content but through conventional method. Findings showed a significant development in the computational thinking especially in algorithmic thinking and abstraction. Thus a STEAM approach learning environment is one of the effective methods of teaching that improved computational thinking.
\end{abstract}

Keywords—Computational thinking skills, (STEAM) approach, algorithmic thinking, abstraction, decomposition, generalization, Jordan.

\section{$1 \quad$ Introduction}

The huge growth of Information and Communication Technology (ICT) and the ubiquitous influx of digital technologies, such as smart phones and online games, characterize societies of the 21 st century [1]. There has been a broad call to provide today's learners with the essential skills that are expected to make them competitive in future jobs that cannot be precisely determined in an everlasting evolving technologi- 
cal landscape. One of these skills is the computational thinking. It is not limited to coding knowledge; rather, it seeks to make people think like computer scientists and engineers [2]. It is not restricted to computerizing curricula or trying to attract students to computing topics, but rather to grafting subjects that students already have with the skills involved in analytical thought activities. Therefore, computational thinking is about formulating solutions to problems in diverse contexts of everyday life, even in the absence of computational devices. Embedding computational thinking in curricula is not straightforward; each discipline has its own outcomes, and those outcomes cross the boundaries between disciplines [3]. Here rises the significance of the science, technology, engineering, arts and mathematics (STEAM) approach, which properly ties disciplines together technologically and provides a precious pool of current and future-oriented, socially and economically stimulating skills that lead to growth and innovation [4].

\section{$2 \quad$ Literature Review}

\subsection{Definitions and perspectives of computational thinking}

The inclusion of computational thinking in education has grabbed attention over the last decade; hence the process of embedding it in the classroom is still in its infancy [3]. In addition to the lack of a common clear definition of computational thinking among educators, there is no agreement on the nature of this inclusion in the curricu$\operatorname{lum}[5]$.

The physicist Kenneth Wilson was the first introduced computational thinking in 1982 in the science fields [6]. In 2006 [7] brought the term again to public as she emphasized on its importance in education for both university students and K-12 students, as it is becoming an essential skill to succeed in the 21 st century. According to her, students who learn computational thinking across the curriculum can begin to see a relationship between academic subjects, as well as between life inside and outside the classroom. Computational thinking includes: Decomposition: Breaking down data, processes, or problems into smaller and manageable parts; Pattern recognition: Observing patterns, trends, and regularities in data; Abstraction: Identifying the general principles that generate patterns; Algorithmic thinking: Developing step by step instructions for solving problems [8].

On 2011, The International Society for Technology in Education (ISTE) [9] and The Computer Science Teachers Association (CSTA) defined computational thinking with a perspective close to [8] perspective. They defined it as a process of problemsolving [10] that includes: organizing and analyzing data logically; formulating problems in a way that can be solved by the help by tools such as computer; representing data through abstractions such as models and simulations; automating solutions through algorithmic thinking (a series of ordered steps); identifying, analyzing, and implementing possible solutions with the goal of achieving the most efficient and effective combination of steps and resources; generalizing and transferring this problem- solving process to a wide variety of problems. These skills are supported by a 
number of attitudes, these attitudes include: confidence in dealing with complexity; persistence in working with difficult problems; tolerance for uncertainty; the ability to deal with open ended problems; the ability to communicate and work with others to achieve a common goal or solution. [9] Suggested problem-solving, examining pattern, and questioning evidence as main skills in computational thinking. [11] Proposed collecting, analyzing, representing data, decomposing problems, algorithms, and making simulations. Moreover, skills such as creating, collaborating, and ability to work with others were proposed by [12]: [13] and [14].

\subsection{Assessing advances in computational thinking}

As there is an increasing emphasis on the need to develop computational thinking among learners; practices, frameworks, and assessment of computational thinking inside or outside the classroom are in continuous developing process. These are influenced by the researchers' perspective of computational thinking. Two main views regarding practices and assessment of computational thinking concepts emerged. The first view was within the context of computer science, informatics, computer gaming, technology, engineering and computing [15];[16];[17];[18];[19];[20]; [21]; [22] and [23], This view focused on the employment of assessments based on tools such as Scratch, Alice, Bebras challenge, robotics, video games, and use of criteria related to programming and coding. The second view was within the context of science and mathematics [24] and [25]. This study followed a mixed of both views.

\subsection{STEAM term definition}

The origin of STEM term was in 1990's by the National Science Foundation (NSF) in USA. In many educational reforms that take place today, STEM was considered as a supportive approach that emphasized on the multidisciplinary approach to better prepare students for STEM occupations and to compete in the global economy [22]. STEM Approach can be defined as a paradigm that emphasis on teaching a subject by grafting the four disciplines in a planned- integrated way. This approach is conducted in a well-established environment with suitably prepared instructor. The classroom appears as a group of clusters of collaborating and actively communicating learners with the goal of empowering them with the 21 st century skills. Coupled with Arts discipline, STEM paradigm is shifting to become STEAM. The debate is that Arts may provide learners with new ways of thinking, observing, and more chances of creativity.

\subsection{STEAM integration / education and teacher's role}

There is no question that the role of the teacher in the classroom shifts from the person responsible for designing learning experiences to a facilitator who helps students become accountable for their learning by means of strategies and activities that emphasize problem solving and hypothesis testing [23] in an environment that enhances students levels of motivation as possible. With many skills included like logi- 
cal thinking, critical thinking, reasoning, and collaboration, computational thinking term rises as technology appears in this context.

Undoubtedly, the successful integration of disciplines relies on the teacher. When we discuss conceptualizing STEAM education/integration in schools, and the available opportunities of implementing it in classrooms, we need to pinpoint some issues, such as teacher and administration beliefs towards learning. Planned activities reflect school visions regarding STEAM, and these visions differ from school to another. Teachers conceptualize STEAM education in different ways or models; some of them may focus on science as the core subject that steers the whole process, while other subjects (mathematics, technology, arts, and engineering) would contribute to science learning. Other teachers might teach all subjects in the same class but with low levels of integration [24]. Another important issue is the teacher's background, experience, and knowledge which are essential to integrate disciplines effectively [25]. Add on teacher's willing to develop in career; some teachers keep on working within traditional methods and refuse any extra work and preparation that result in an overload. So the true STEAM education should enhance students' understanding of how things work, improve their use of technology, introduce them more to engineering during high school, and help them develop skills and abilities regarding design process [26].

With this notation the objective of this study was to measure the efficacy of using STEAM-driven learning environment in developing computational thinking among high school learners.

\subsection{STEAM and computational thinking}

Computational thinking harmonizes with mathematical and engineering thinking. Computer science naturally draws on mathematical thinking, its foundation rest on mathematics [27]. STEAM disciplines also relate tightly to computational thinking by using visualizing and interactive tools and on-line websites that expose students' minds to complex systems (such as NetLogo) and simulation (such as PhET webbased source). For example, these resources can be used within a biology lesson to integrate with math skills like probability, and at the same time enhancing student's understanding of complex systems, which is one of the suggested skills of computational thinking. Computational thinking, which encompasses strategies for problem analysis and solution design, is highly applicable in all STEM disciplines. Schools and colleges that implant STEAM within their curricula are already developing computational thinking during teaching process in many aspects [28]. In other words, the interaction between STEAM disciplines draws computational thinking skills [29].

\subsection{Previous studies}

Bati, Caliskan, Gunes, Sacan, \& Yestisir [30] conducted a research to develop a STEAM-based program for teaching middle school students in a public school in Turkey the concept of time to enhance their computational thinking skills. They proposed Time Teaching Program (TTP) in which they delivered the time concept in many views (mathematics view, physics view, and history view) in the form of mod- 
ules and activities. They used quasi-experimental method pretest-post-test control group and observational case study. Data was collected through computational thinking test, observations, and interviews. Results showed a positive significant effect of STEAM- based program on computational thinking skills of the learner.

Kotzampasaki and Psycharis [31] conducted an empirical research that aimed to study the impact of a STEM-content inquiry-based method using educational games and tools, such as Arduino kits, to develop computational thinking on (115) students in fifth and sixth grades in public schools in Greek. The progress in computational thinking was investigated using questionnaires that were administrated before and after the intervention. Participants of the study were engaged in game learning environment by designing, developing and implementing scenarios using Arduino kits. The results showed a positive influence on the dimensions of computational thinking among students in the experimental group.

Lepage, Lille, and Romero [32] conducted a study that aimed at investigating the effect of programming on computational thinking skills (they related computational thinking to the creative use of digital technologies to solve problems) for higher education in Canada. Total of (120) undergraduate students with no background on programming were taught how to use 'story2code' and their projects were assessed by 'Scratch' which is an automatic code analysis tool. The results showed that creativity and computational thinking skills with very high percentages.

Bers and Sollivan [33] explored the efficiency of educational robotics that are used for students from pre-kindergarten to grade two in Boston, and the study included (60) kids who used appropriately KIWI robotics and tangible coding tools for eight weeks course. Children were able to master basic robotics and programming skills, while the older children were able to master increasingly complex concepts using the same robotics kit in the same amount of time. The results showed a significant mastery in design and programming as part of computational thinking skills.

Games, Richards, and Min [34] conducted a study that aimed at setting the design and development, the instruction, and evaluation of digital game-based as after school activities in middle school in Taiwan. Students participated in a workshop that was conducted after school and they were asked to design a game, they learned, as they were involved in that activity the researcher investigated the appearance of computational skills such as: logical thinking, abstracting and problem solving. The results showed that students were able to perform decomposition, pattern recognition, generalization, abstraction and data visualization in scenarios outside digital game based learning environment.

Bani-Matar [35] conducted a qualitative research that aimed at identifying the characteristics of the abstraction processes that grade (9) students perform when they are involved in conducting an activity of modelling of a topic in Mathematics in Palestine. With the aid of technology specifically the GeoGebra tool and based theoretically on the model of Abstraction in Context (AiC), three groups of students were involved in a modeling activity in the circle topic, and went through the four stages of AiC model (need, recognizing, building with, constructing and consolidating). The results showed that students were able to reach abstraction of mathematical concepts, where students will work, collaborate, code and analyze in classroom environment. 


\section{$3 \quad$ Methodology}

\subsection{Participants}

The participants were students of 10th grade with a total number of 32 . The individuals of the sample were randomly distributed into two groups; control and experimental. The control group consisted of (19) students who studied using conventional method, while the experimental group that consisted of (13) student studied using STEAM approach.

\subsection{Instruments of the study}

The researcher developed Computational Thinking Skills Test that was used as a pre and posttest to measure the level of the four skills of computational thinking: decomposition, abstraction, pattern recognition, and algorithmic thinking. After viewing previous work on assessment tools and tests, the researcher developed a test based mainly on the UK Bebras Computational Thinking Challenge.

\subsection{The instructional strategies of the study}

The Conventional Method in Teaching Geography Skills: This method focused mainly on the use of the worksheets conducted from geography past papers (previous tests provided by Cambridge University Press and used as worksheets for students). It used lecturing and question-answer method. Students interacted with geography past papers and with each other, as well as with the instructor. This method was used with the control group.

The STEAM Approach in Teaching Geography Skills: This method used the integration of science, technology, engineering, arts, and mathematics in teaching the requested geography skills. STEAM approach was chosen by the researcher because this approach does not only lead to precious knowledge in the topic being taught, but also several skills and qualities such as critical thinking, communications, responsibility, spatial thinking would also be developed. Aligned with those skills that are of interest of the researcher, STEAM approach was found to be the best practice that could lead the lessons planned. The researcher perspective of STEAM approach was based on the idea of linking math, physics, technology, and engineering to the learning of geography skills. Math and physics were spotted in the approach as students performed scaled drawings, units' conversion, area calculation, and four directions interpretations. Technology was spotted through the use of materials that enhanced students' learning such as, papers, pencils, rulers, ropes, and calculators. Engineering process took place when students had their own maps designed, produced, tested, and modified. This method was used with the experimental group.

In the LightBot activity conducted for this study, students were asked to give directions (commands) to their little bot to light up all blue tiles. Students learned the s of coding using drag and drop icons on the main screen of the puzzle. The icons were: 
move forward, turn right, turn left, light up, jump, and repeat (using loops in advanced stages of the game). The stages were ordered based on their difficulty from s, to procedures and then to loops. The player needed to bear in mind how complex a path is, how many blue tiles shall be lit up, how the squares are distributed in the path, and what is the order of icons or commands to be used. In each stage there was a limited number of available space on the screen to place the commands in (for example, (12) empty spaces in s stage, (20 -28) empty spaces in procedures stage, and (17) empty spaces in the loop stage) which means than students needed to use commands effectively to solve the puzzle. The importance of this activity was pivoted on the fact that learners can benefit from risk-free environment available in this type of games, as well as having more than one correct answer for a certain puzzle. Here the students were observed comparing their solution with each other, trying to validate and compare their codes to see which code was most effective.

In the Map Activity conducted for this study, the students were asked, in groups, to draw a fully scale map of their classroom, using measuring tools, white sheets of papers and pencils. Students learned many concepts and skills (which are included in geography) related to mathematics, geography, physics and spatial thinking, such as scale drawing, vectors and scalars, units conversion, SI units, the four directions (North, South, East, and West) reference, four-grid reference, measurements of straight and curved distances, and map keys (map legend). While performing this activity, they applied abstraction as they ignored some irrelevant factors to the map such as desk colors, desks heights, and table heights. On the other hand, they focused on relevant factors such as desk width and length, teacher table width and length, distance between desks, distance between door and desks. They utilized the tiles dimensions on the floor to make the measurements of distances easier. Then, they were given printed maps of some part in a city as well as pencils, ropes, rulers, transparent sheets. They were asked to do some measurements, draw paths from a start point to an end.

In the OS Map Activity, (on-line website similar to Google Maps), students learned how different maps of the same region can exist. Such maps are transportation network map, settlement map, greenspace map, cycle network map, Aerial (2-D, and 3D) map, and leisure map (most detailed map). Abstraction was emphasized in this activity through comparing each type of OS map, finding that some items that were shown in one type were removed in other types based on the purpose of the map.

\subsection{Data analysis}

To answer the question of the study, the Statistical Package for the Social Science (SPSS) was used to analyze the data collected and to test the hypothesis set, using descriptive statistics such as:

1. The arithmetic mean: This was a measure of central tendency and was used to compare the average of responses of students on the computational thinking test for both control and experimental groups. 
2. The standard deviation: This was a measure of variability and was used to measure the deviations in the responses of students in control group and experimental group.

3. Four way (MANCOVA): This statistical analysis was used to test whether the differences between the individuals' responses in the tests were statistically significant or not.

4. One way (ANCOVA): This statistical analysis was used to determine the differences on performance due to STEAM approach as a teaching method on computational thinking skills.

5. The (partial) Eta square was used to determine the effect size of the independent variable used which is the teaching method on computational thinking.

\section{$4 \quad$ Study Procedures}

The researcher developed the following steps in order to fulfill the study aims:

1. The researcher reviewed relevant literature and previous studies that assisted the preparation of the current study's literature review and procedures.

2. The study instrument was developed by the researcher.

3. The validity of the instrument was assured by a number of experts in curriculum and instruction, educational technology, Computer Science (CS), and STEAM education.

4. The appropriate formal consents were obtained after intentionally choosing the school at which the researcher conducted the study.

5. The two groups of the study (experimental and conventional) were chosen randomly among 10th grade students.

6. To verify the reliability of the instrument the researcher administrated the Computational Thinking Skills Test on a pilot sample from the population of the study but outside the sample.

7. The pre-test of Computational Thinking Skills were conducted upon both groups of study.

8. Results of T-test were used to decide whether the two groups of study were equivalent prior to treatment.

9. Students of both groups were trained on the geography skills by the researcher, who used lecturing and direct teaching with the control group, and STEAM approach with the experimental group.

10. The treatment lasted for 6 weeks during the first school semester 2019/2020

11. The post-test of computational thinking skills test were conducted upon both groups.

12. Students' scores on the instrument (pre and post) were collected and analyzed using SPSS.

13. Results and findings were analyzed and discussed 


\section{$5 \quad$ Results}

The study question:

What is the effect of using STEAM approach on developing computational thinking at the level of $(\alpha=0.05)$ among 10th grade students in Jordan?

To answer this question, means and standard deviations on the performance of the two study groups, on the total score of the computational thinking skills were calculated. Table 1 shows the results (the total grade on the test was 8).

Table 1. Means and Standard Deviations on the Performance of the Two Study Groups, on the Total Score of the Computational Thinking Skills Pretest and Posttest

\begin{tabular}{|l|c|c|c|c|c|}
\hline \multirow{2}{*}{ Group } & \multirow{2}{*}{$\mathbf{N}$} & \multicolumn{2}{c|}{ Pretest } & \multicolumn{2}{c|}{ Posttest } \\
\cline { 3 - 6 } & & Mean & SD & Mean & SD \\
\hline Experimental & 13 & 3.15 & 2.115 & 5.54 & 1.984 \\
\hline Control & 19 & 3.63 & 2.385 & 4.11 & 2.132 \\
\hline Total & 32 & 3.44 & 2.257 & 4.69 & 2.162 \\
\hline
\end{tabular}

Table 1 indicates an apparent difference between the means on the performance of the two study groups on the total score of the computational thinking skills posttest. The mean of the experimental group who studied using STEAM approach was (5.54), which was higher than the mean of the control group who studied using conventional method (4.11). To determine whether the difference between the means of the two study groups was statistically significant, the analysis of covariance (ANCOVA) was used as shown in Table 2.

Table 2. The (ANCOVA) Analysis on the Performance of the Two Study Groups on the Total Score for the Computational Thinking Skills Posttest

\begin{tabular}{|l|c|c|c|c|c|c|}
\hline \multicolumn{1}{|c|}{ Source } & Sum of Squares & Df & Mean Square & F & Sig. & $\begin{array}{c}\text { Partial } \\
\text { Eta Squared }\end{array}$ \\
\hline Pretest & 90.192 & 1 & 90.192 & 67.363 & .000 & \\
\hline Group & 24.629 & 1 & 24.629 & 18.395 & $.00^{*}$ & .388 \\
\hline Error & 38.828 & 29 & 1.339 & & & \\
\hline Corrected Total & 144.875 & 31 & & & & \\
\hline
\end{tabular}

The value of $(\mathrm{F})$ related to the teaching method was (18.395), at a level of significance less than (0.05), which indicates that there is a statistically significant difference between the means of the two study groups according to the teaching method (STEAM approach vs conventional method) on the total score for the computational thinking posttest.

Table 2 shows that the effect size of the teaching method was $(0.388)$ which means that $(38.8 \%)$ of the variance on the total score on the computational thinking skills posttest was due to the teaching method that used STEAM approach, and (60.2\%) was due to other factors that were not studies in this research. Finally, these results showed that there is a positive effect of using STEAM approach in developing computational thinking skills among 10th grade students. 
In addition, means and standard deviations on the performance of the two study groups, on all skills of interest of the computational thinking skills posttest were calculated. Table 3 shows the results.

Table 3. Means and Standard Deviations on the Performance of the Two Study Groups on Skills of Computational Thinking Pretest and Posttest

\begin{tabular}{|c|c|c|c|c|c|}
\hline & \multirow{2}{*}{ Group } & \multicolumn{2}{|c|}{ Pretest } & \multicolumn{2}{|c|}{ Posttest } \\
\hline & & Mean & SD & Mean & SD \\
\hline \multirow{3}{*}{$\begin{array}{l}\text { Generalization } \\
\text { (Pattern Recognition) }\end{array}$} & Experimental & .62 & .506 & .92 & .277 \\
\hline & \begin{tabular}{|l|} 
Control \\
\end{tabular} & .47 & .513 & .79 & .419 \\
\hline & Total & .53 & .507 & .84 & .369 \\
\hline \multirow{3}{*}{ Decomposition } & Experimental & 1.54 & .877 & 1.38 & .870 \\
\hline & Control & 1.47 & .964 & 1.47 & .964 \\
\hline & Total & 1.50 & .916 & 1.44 & .914 \\
\hline \multirow{3}{*}{ Algorithmic Thinking } & Experimental & .77 & .927 & 2.46 & .967 \\
\hline & \begin{tabular}{|l|} 
Control \\
\end{tabular} & 1.58 & 1.017 & 1.74 & 1.098 \\
\hline & Total & 1.25 & 1.047 & 2.03 & 1.092 \\
\hline \multirow{3}{*}{ Abstraction } & Experimental & .23 & .439 & .77 & .439 \\
\hline & Control & .11 & .315 & .11 & .315 \\
\hline & Total & .16 & .369 & .38 & .492 \\
\hline
\end{tabular}

Table 3 indicates an apparent difference between the means for the performance of the two study groups on all skills of interest of the computational thinking skills posttest.

The mean of the experimental group who studied using STEAM approach was higher than the mean of the control group who studied using conventional method in all skills except the decomposition skill in which the control group mean was higher than the mean of the experimental group. To determine whether the difference between the means of the two study groups was statistically significant, the multiple analysis of covariance (MANCOVA) was used as shown in Table 4.

Table 4. The (MANCOVA) Analysis on the Performance of the Two Study on All Skills of Computational Thinking Posttest

\begin{tabular}{|l|l|c|c|c|c|c|c|}
\hline Source & Dependent Variable & $\begin{array}{c}\text { Sum of } \\
\text { Squares }\end{array}$ & df & $\begin{array}{c}\text { Mean } \\
\text { Square }\end{array}$ & F & Sig. & $\begin{array}{c}\text { Partial } \\
\text { Eta Squared }\end{array}$ \\
\hline \multirow{5}{*}{ Group } & Generalization & .062 & 1 & .062 & .448 & .509 & .017 \\
\cline { 2 - 8 } & Decomposition & .009 & 1 & .009 & .025 & .876 & .001 \\
\cline { 2 - 8 } & Algorithmic Thinking & 8.224 & 1 & 8.224 & 14.497 & $.001^{*}$ & .358 \\
\cline { 2 - 8 } & Abstraction & 2.043 & 1 & 2.043 & 24.645 & $.000^{*}$ & .487 \\
\hline
\end{tabular}

Table 4 shows that $(F)$ value in relation to the teaching method was $(0.448)$, at the level of significance $(0.509)$ for the generalization skill, and was $(0.025)$ at the level of significance (0.876) for the decomposition skill. This means that there was no statistical significant difference between the means of both groups of study in those two skills according to teaching method (STEAM approach vs conventional method). In addition, Table 4 shows that (F) value in relation to the teaching method was (14.497) 
at the level of significance less than (0.05) for the algorithmic thinking skill, and was (24.645) at the level of significance less than (0.05) for the abstraction skill. This means that there was statistical significant difference between the means of both groups of study in those two skills according to teaching method (STEAM approach vs conventional method. Finally, these results showed that there is a positive significant effect of using STEAM approach in developing algorithmic thinking and abstraction skills, and no significant effect in developing decomposition and generalization skills.

\section{Discussion}

\subsection{Discussion related to algorithmic thinking skill result}

The higher mean in the algorithmic thinking in the experimental group, compared to that in the control group, in the posttest, was due to the fact that the LightBot resource, (an on-line puzzle included as part of the STEAM approach), used during treatment, played a significant role in developing the algorithmic thinking skill used by students to solve problems, by applying step-by-step solutions. This development was reflected on their answers to the test, particularly, items (3), (6), and (7) where they were able to perform algorithmic thinking in scenarios outside digital-game based learning environment. Item (6), for example, asked the student to direct three robots at the same time in a maze, so that each robot could reach certain object using commands: North, South, East and West (clear sense of the four directions is an important Geography skill, and its development was one of the researcher's interest in this study). Item (7), for example, asked the student to run a certain code (including the text commands: IF, THEN, and ELSE) in order to decide where the football game mentioned in the item will be played. Based on the rolling of a six-sided dice three times, and comparing numbers appear in each roll, students were able to decide where the football game would be played. Item (3), for example, suggested a certain condition to text a valid license plate of a car, which the students shall use to compare different plate texts and find out which of them were valid plates. These findings agreed with [35], whose results showed significant development in algorithmic thinking, and problem-solving skills among students who were involved in digital game-based learning environment. In addition, this study results agreed with [30], whose findings stated that the STEAM-based program significantly improved the computational thinking skills of eighth-grade middle-school students. In addition, the results agreed with [31] who found out that STEAM inquiry game learning (they used Arduino kits) had a significant positive influence on the computational thinking skills and their confidence with computation. Results of [33] agreed with the researcher's results, where the use of educational games and robotics enhanced students' levels in dealing with complex situations and strengthened their computational thinking skills. Results of [32], who used programming environment, scratch, with undergraduate students with low or no background in programming experience, showed high computational think- 
ing levels among experimental group which also agreed with the researcher's findings.

\subsection{Discussion related to abstraction skill result}

The higher adjusted mean in the abstraction skill calculated in the experimental group compared to the mean found in the control group in the posttest was due to the Map activity conducted as part of the STEAM approach used in the experimental group. The development in abstraction was observed in students' written responses in items (4) in the posttest. This item showed a map sample on traffic transportation in a town (one-way and two-ways streets), and how drivers may take routes to reach different destinations. Students used the map sample to move correctly from position to another. These also measured their ability in generalizing and applying the map sample to the real city map. Applying of abstraction skill (defined as process of simplifying situation or problem that is complicated by ignoring unnecessary information and details) was observed through neglecting other invalid routes while moving in the valid ones. These results agreed with [34], [35] and [36] who used digital educational environment to teach students mathematics and improve their abstraction level and applying it in the math class.

\section{$7 \quad$ Conclusion and Recommendations}

\subsection{Conclusion}

Among 10th grade students studying geography in Jordan:

1. There was a positive significant effect of using STEAM approach on the computational thinking skills in general and on algorithmic thinking skill and abstraction skill in particular.

2. There was no significant effect of using STEAM approach on the generalization skill, and the decomposition skill.

\subsection{Recommendations}

Embedding STEAM approach is becoming a growing demand to enhance learning process and scaffold learners' thinking abilities, so that we, as educators, can help preparing them appropriately for their future. Accordingly, the researcher recommended the following in the light of this study

1. There shall be a continuous guidance for the teachers regarding ways and activities that make the embedding of STEAM approach in different subjects more applicable.

2. The utilizing of STEAM approach in different subjects does not mean to get rid of conventional method at all. Some topics allow embedding of STEAM approach 
easily and clearly (such as mathematics, science, ICT). In other subjects such as Humanities including geography, history, civics, arts, the embedding of STEAM approach sounds harder. The teacher shall be aware of the extent to which STEAM approach can be used in the learning process.

3. Humanities subject's teachers (geography, science, history, civics, and arts) can benefit from using STEAM approach, by focusing on the skills (such as perceptual abilities, skilled movements, nondestructive communication movements involved in the subject they teach rather than the knowledge.

\section{$8 \quad$ References}

[1] Esteve-Mon, F., Llopis, M., \& Adell-Segura, J. (2020). Digital Competence and Computational Thinking of Student Teachers. Retrieved on January 20, 2020 from https://doi.org/ 10.3991/ijet.v15i02.11588

[2] Bati, K. (2018). Computational Thinking Test (CTT) for Middle School Students. Mediterranean Journal of Educational Research, 12(23), 89-101. https://doi.org/10.29329/mjer.20 $\underline{18.138 .6}$

[3] Bocconi, S., Chioccariello, A., Dettori, G., \& Ferrari, A., et al. (2016). Developing Computational Thinking in Compulsory Education. Retrieved on January 19, 2019 from: https://publications.jrc.ec.europa.eu/repository/bitstream/JRC104188/jrc104188_computhi nkreport.pdf

[4] English, L. (2016). STEM Education K-12: Perspectives on Integration. International Journal of STEM Education, 3(3), 1-8.

[5] Koh, J., Lye, S. (2014). Review on teaching and learning of computational thinking through programming: What is next for K-12? ELSEVIER, 44, 51-61. https://doi.org/10.10 16/j.chb.2014.09.012

[6] Denning, P. (2017). Computational Thinking in Science. The Scientific Research Society, 13-17. Retrieved on October 5, 2018 from: http://denninginstitute.com/pjd/PUBS/AmSci2017-ct-Science.pdf

[7] Wing, J. (2006). Computational Thinking. Communications of the ACM, 49(3), 33-35.

[8] Computing At School (CAS). (2015). What is Computational Thinking? Retrieved on October 10, 2018 from: https://computationalthinkingcourse. withgoogle.com/unit?lesson=8\& $\underline{\text { unit }=1}$

[9] International Society for Technology in Education (ISTE) (2016). How Have the ISTE Standards for Students Evolve? Retrieved on September 1, 2018 from: https://www.iste. org/standards/for-students

[10] Wang, W., \& Wang, Y. (2016). A Study on Computer Teaching Based on Computational Thinking. Retrieved on March, 2019 from: https://doi.org/10.3991/ijet.v11i12.6069

[11] Charlton, P., \& Luckin, R. (2012). Time to re-load? Computational Thinking and Computer Science in.The London Knowledge Lab. Retrieved on March 20, 2019 from: https://knowledgeillusion.files.wordpress.com/2012/03/time-toreloadwhattheresearchsaysbriefing27april2012.pdf

[12] Gretter, S., \& Yadav, A. (2016). Computational Thinking and Media \& Information Literacy: An Integrated Approach to Teaching Twenty-First Century Skills. TechTrends, 60(5), 510-516. https://doi.org/10.1007/s11528-016-0098-4

[13] Woollard, J. (2016). CT Driving Computing Curriculum in England. CSTA: The Voice of K-12 Computer Science Education and its Educators, 12(1), 4- 5. 
[14] Allan, W., Coulter, B., Denner, J., Erickson, J., Lee, I., Malyn-Smith, J. et al., (2011). Computational Thinking for Youth Practice. ACM Inroads, 2(1), 32-37. https://doi.org/10. $\underline{1145 / 1929887.1929902}$

[15] Boljat, I., \& Bubica, N. (2018). Assessment of Computational Thinking, Proceedings of the International Conference on Computational Thinking Education 2018. Hong Kong: The Education University of Hong Kong, 121-124.

Dorling, M., Selby, C., \& Woollard, J.(2014). Evidence of Assessing Computational Thinking. Retrieved on June 19, 2019 from: https://eprints.soton.ac.uk/372409 /1/372409EvidAssessCT.pdf

[17] Bienkowski, M., Grover, S., Rutstein, D. W., \& Snow, E. (2015). Assessment Design Patterns for Computational Thinking Practices in Secondary Computer Science: A first Look (SRI Technical Report). Menlo Park, CA. Retrieved from: https://pact.sri.com/downloads /Assessment-Design-Patterns-for-Computational\%20Thinking-Practices-SecondaryComputer-Science.pdf

[18] Lockwood, J. \& Mooney, A. (2018). Developing a Computational Thinking Test Using Bebras Problems. TACKLE: the 1st Systems of Assessments for Computational Thinking Learning workshop at EC-TEL 2018 Conference, Leeds, United Kingdom

[19] Asunda, P. (2018). Infusing Computer Science in Engineering and Technology Education: An Integrated STEM Perspective, The Journal of Technology Studies. Retrieved on June 29,2019from:https://www.researchgate.net/publication/329820901_Infusing_Computer_Sc ience in Engineering and Technology Education An Integrated STEM Perspective. https://doi.org/10.21061/jots.v44i1.a.1

[20] Moreno-León, J., Robles, G., \& Román-González, M. (2017). Complementary Tools for Computational Thinking Assessment. Proceedings of the International Conference on Computational Thinking Education (CTE 2017). The Educational University of Hong Kong, 154-159. https://doi.org/10.1007/978-981-13-6528-7_6

[21] Kim, B., Kim, J., \& Kim, T. (2013). Paper-and-Pencil Programming Strategy Toward Computational Thinking for Non-Majors: Design Your Solution, Journal of Educational Computing Research, 49(4), 437-459. https://doi.org/10.2190/ec.49.4.b

[22] Thomasian, J. (2011). Building a Science, Technology, Engineering, and Math Education Agenda. Washington: National Governors Association. Retrieved on September 9, 2018 from: https://files.eric.ed.gov/fulltext/ED532528.pdf

[23] Gujjar, A. \& Naoreen, B. (2009). Role of Teacher as Classroom Manager. I-Manager's Journal on Educational Psychology, 2(4), 65-73.

[24] Dare, E., Ellis, J., Roehrig, J. (2018). Understanding Science Teachers' Implementations of Integrated STEM Curricular Units Through A Phenomenological Multiple Case Study. International Journal of STEM Education, 5 (4), 1-19. https://doi.org/10.1186/s40594-018$\underline{0101-\mathrm{Z}}$

[25] Moore, T., Roehrig, G., \& Stohlmann, M. (2012). Considerations for Teaching Integrated STEM Education. Journal of Pre-College Engineering Education Research (J-PEER). 2(1), 28-34. https://doi.org/10.5703/1288284314653

[26] Bybee, R. (2010). What is STEM Education? American Association for the Advancement of Science (AAAS) 329(5995), 996. Retrieved on January 19, 2019 from: http://science.sciencemag.org/content/329/5995/996 https://doi.org/10.1126/science.1194 $\underline{998}$

[27] Abdul Taleb, C., \& Aliyu, F. (2019). Enhancing Students' Reasoning Skills in Engineering and Technology through Game-Based Learning. Retrieved on February 10, 2020 from: https://doi.org/10.3991/ijet.v14i24.12117 
[28] García-Peñalvo, F. J. (2016). What Computational Thinking Is. Journal of Information Technology Research, 9(3), 5-8.

K-12 Computer Science Framework Committee (2016). K-12 Computer Science Framework. Retrieved on September 1, 2019 from:https://k12cs.org/wpcontent/uploads/2016/09/K\%E2\%80\%9312-Computer-Science-Framework.pdf

[29] Bati, K., Caliskan, I., Gunes, G., Sacan, E., \& Yestisir, M. (2018). Teaching the concept of time: steam-based program on computational thinking in science education. Journal of Cogent Education, 5(1), 1-16. https://doi.org/10.1080/2331186x.2018.1507306

[30] Kotzampasaki, E., \& Psycharis, S. (2018). The Impact of a STEM Inquiry Game Learning Scenario on Computational Thinking and Computer Self-confidence. EURASIA Journal of Mathematics, Science and Technology Education, 15(4), 1-18. https://doi.org/10.29333/ej mste/103071

[31] Lepage, A., Lille, B., \& Romero, M. (2017). Computational Thinking Development through Creative Programming in Higher Education. International Journal of Educational Technology in Higher Education, 14(42), 1-15. https://doi.org/10.1186/s41239-017-0080-z

[32] Bers, M. \& Sollivan, A. (2014). Robotics in the Early Childhood Classroom: Learning Outcomes from an 8-Week Robotics Curriculum in Pre-Kindergarten through Second Grade. International Journal of Technology and Design Education, 26(1), 3-20. https://doi. org/10.1007/s10798-015-9304-5

[33] Games, A., Richards, K., \& Min, W. (2011). Examining Digital Game-Based Learning through the Lens of 21st Century. Proceedings of the SITE 2011--Society for Information Technology \& Teacher Education International Conference held in Nashville, Tennessee on March 7-11, 2011.

[34] Bani-Matar, H. (2014). Abstraction Processes of Grade 9 Students in Modelling Activities (A Qualitative Research). Unpublished thesis, An-Najah National University, Nablus, Palestine. (In Arabic)

\section{Authors}

Rana Al-Haj Bedar is a Physics Teacher, The International Department, Philadelphia National Schools, Jordan. Master's Degree Holder in Educational Technology, The University of Jordan. (e mail: eng.rana86@yahoo.com).

Prof. Muhannad Al-Shboul is a Vice Dean for Quality Affairs and Development, School of Educational Sciences, The University of Jordan, Amman, CO 11942 Jordan (e-mail: malshboul@ju.edu.jo).

Article submitted 2020-04-08. Resubmitted 2020-05-22. Final acceptance 2020-05-23. Final version published as submitted by the authors. 